Canadian Journal of Family and Youth, 6(1), 2014, pp 1-28

ISSN 1718-9748 () University of Alberta

http://ejournals.library.ualberta.ca/index/php/cjfy

\title{
Leaving Home: A Qualitative Study
}

\author{
Mann-Feder, V.R., Eades, A., Sobel, E. \& DeStefano, J.
}

\begin{abstract}
This article presents the results of a qualitative study that examined first person accounts of the process of leaving home in Emerging Adulthood. Thirty university students aged 21 to 26, who attended a large commuter school in a Canadian city, were interviewed individually. Sixteen had already left home to live on their own, while fourteen lived with their families but anticipated leaving home. What emerged was a model of home leaving as a gradual process, which spanned months or years and represented a significant transition. Adaptation was either facilitated or impeded by external supports as well as personal attitudes and abilities. While parents played an important role in how confidently participants experienced the transition, peers appeared to have exerted a unique and important influence as sources of information and reassurance. Implications for practice and research are identified.
\end{abstract}

Varda Mann-Feder is Professor of Applied Human Sciences at Concordia University. Dr. Mann-Feder is known across Canada for her research on aging out of care and her advocacy on behalf of youth in placement. She is Vice President of the Child and Youth Care Accreditation Council of Canada and was a member of the founding board for the Society for the Study of Emerging Adulthood. Most recently, she provided a webinar for the child welfare system in Ontario that was broadcast to forty five points of service in Ontario, Manitoba and Inuvik. Dr. Mann-Feder's most recent SSHRC funded research focuses on turning points in home leaving that can inform programs of preparation for youth leaving care and the role of peer relationships in adjustment, particularly in relation to transitions to adulthood for youth placed in the public system. Allison Eades has been conducting psychosocial research since 2008 and is currently employed at Baycrest's Community Day Centre for Seniors. Having earned a Master's degree in Human Systems Intervention (Concordia University) and a certificate in Conflict Analysis and Intervention, Allison has gained significant research and facilitation experience in diverse interprofessional settings. Her work experience has been in the private, public, and non-profit sectors both nationally and internationally. Her areas of interest are team performance, interpersonal relationships across the lifespan, and the impact of psychosocial interventions. Emma Sobel is passionate about pursuing innovative solutions to social issues. She currently works for a small consultancy called ICA Associates, Inc. and is an active member of the emerging social innovation community in Toronto. She began her career as a summer camp director where she became interested in group development and system dynamics. She experimented with ways to work collaboratively with staff to address organizational issues, the result of which was a successful anti-bullying program. She went on to complete a degree in Human Systems Intervention from Concordia University and since then has focused her work on addressing social challenges in Aboriginal communities, education systems, public health and federal and provincial levels of government. This is her first publication and she is grateful to have had the opportunity to work with Dr. Varda Mann-Feder, an esteemed researcher, guide, mentor and friend. Jack De Stefano, EdD. is the director of the Psychoeducational and Counselling Clinic in the Department of Educational and Counselling Psychology at McGill University. He is also on the faculty of the School and Counselling Psychology programs. His areas of research interest include the training and clinical supervision of professional counsellors and psychologists. He is licensed as a psychologist in Quebec where he provides psychotherapy services to individuals and families as well as clinical supervision of mental health professionals.

Author's note: This research was made possible by funding from the Social Sciences and Humanities Research Council of Canada. 
Mann-Feder, Eades, Sobel, \& DeStefano

\section{Introduction}

Leaving home has long been viewed in Western cultures as an important milestone that signals entry into adulthood (Mulder, 2009). This article presents results of a qualitative study of home leaving, the goal of which was to advance understanding of how readiness to live independently develops in a normative population. Preparation for living on one's own has been a major focus of intervention with youth who populate systems of child welfare, juvenile justice, mental health and disability (Mann-Feder, 2011). Despite large investments in programs for transitioning these youth into independent living, outcomes have been poor overall (Tweddle, 2007) and approaches to preparing young people to live on their own have lacked a developmentally informed theoretical base. This study was designed to address current gaps in understanding of what constitutes readiness to live on one's own in early adulthood. It is the first step in a program of research designed to identify critical elements for designing targeted programs and policies that support healthy transitions to adulthood

\section{Review of Relevant Literature}

Over the last twenty years, it has been documented that the transition to adulthood has been delayed among the general population in most parts of the industrialized world (Furstenberg, Rumbaut, \& Settersen, 2005; Proudfoot, 2010). Youth in many developed nations are taking on adult responsibilities later than ever, and the transition itself is more complex, less orderly, and more challenging than before (Osgood, Foster, Flanagan \& Ruth, 2005). This has prompted the proposal of a new life stage, Emerging Adulthood, that differs qualitatively from adolescence or adulthood (Arnett, 2000). 
Leaving Home

The transition from the parental home to one's own home is a milestone that has been delayed considerably among Emerging Adults in Western cultures. The average age for home leaving in Canada, the USA, and in Northern Europe has risen by several years over the last decade, and young people are staying home longer than ever before. A recent report from Statistics Canada stated that $42.3 \%$ of young adults aged $20-29$ lived with their parents as of the 2011 census, as compared with 32.1\% in 1991, and 26.9\%in 1981 (Statistics Canada, 2011). Also significant is that the vast majority of young people in North America now leave home more than once, and do not establish a permanent, autonomous residence until they are almost 30 years old (Mitchell, 2006). Social and economic factors, such as the diminishing number of bluecollar jobs, rising costs of housing and the increasing need for prolonged post-secondary education accompanied by higher tuition fees, have impacted how, when, and why individuals leave home (Clark, 2009; Molgat, 2007). At the same time, it has also been observed that young adults today are less driven to take on adult responsibilities than previous generations and may be less eager to leave their parental home (Lamborn \& Groh, 2009). Quantitative research examining different trajectories and timing for leaving home have been conducted, as have surveys that document the age, reason and extent of social support for home-leaving in many countries (De Marco \& Cosner Berzin, 2008; Molgat, 2002; Seiffe-Krenke, 2010). Some researchers have concluded that home leaving "is a process rather than a one-off event" (Molgat, 2002, p.136) that may even involve a series of processes (La Helma \& Gordon, 2003). Little is known, however, about the factors that influence an individual's perception of their readiness to move out or how leaving home is actually experienced by young people. This study was formulated in response to the need for data that could help elucidate the process of moving out. 
Mann-Feder, Eades, Sobel, \& DeStefano

\section{Methodology}

This qualitative study collected narrative accounts of home leaving through individual semi-structured interviews. Participants were recruited through social science classes at an urban university in a large Canadian city. The university was primarily a commuter school and offered virtually no on-campus housing. Interviews were conducted with 32 volunteers, 20 females and 12 males. None of the participants had ever lived in dormitories. Sixteen of the participants in this study (six males and ten females) had left home and had established autonomous households, mostly with roommates, while the fourteen other participants (four males and ten females) were still living at home but were contemplating leaving. The age of leaving home ranged from 13 to 22, with the majority of participants (59\%) having left between ages of 18 and 20. Participants ranged in age from 21 to 26, with the mean of age of 23.33 for home-leavers and 22.43 for those at home. Two female participants were excluded from the analysis because they had left home to marry. According to data from Statistics Canada (Human Resources and Skill Development Canada, 2013), the age of first marriage has risen significantly over the last thirty years, and leaving home the first time to marry is now a relatively rare trajectory (DeMarco \& Costner Berzin, 2008). Exploring the accounts of married participants was beyond the scope of this study. Four of the sixteen home-leavers who participated had moved out once before with the intention of staying out on their own, although they subsequently returned. A range of ethnicities was represented in the participant group, and four of the home-leavers had moved to a new city or country when they left home. An honorarium was offered for participation and all participants were engaged in an informed consent process, outlining the procedures for insuring anonymity and the freedom to discontinue at any time. 
Semi-structured interviews were conducted with all participants by two trained graduate students. Interview questions were designed to elicit narratives on the following topics: descriptions of the transition to living on one's own, perceptions of readiness, identification of the resources required for a successful transition, and turning points experienced —or anticipated - in the transition to independent living.

All interviews were audiotaped and transcribed. A team of three trained individuals conducted the data analysis using a Consensual Qualitative Research approach (CQR) (Hill, Thompson \& Williams, 1997). This approach emphasizes a systematic team approach to qualitative analysis and the identification of themes across cases. It is particularly well suited to "constructing pathways in the data and constructing theories from the bottom up" (Hill et al., 1997, p.520). Themes and subthemes were identified as general (shared by all participants), typical (cited by the majority, $50 \%+1$ ), or variant (not usual, less than 50\%). Preliminary results were subject to external audit by a researcher skilled in CQR to ensure that all categories were appropriately identified.

In keeping with CQR methodology, which stresses analysis of homogenous groups and separation of samples into subsamples (Hill et al., 1997), the interviews for home-leavers and participants at home were analyzed separately to examine divergences and convergences. The intent was to capture features of the home leaving trajectory as experienced by participants who were at different points of the process. While the research team did not approach the analysis with any particular "expectations" (which Hill et. al, 1997, define as predictions based on previous research), in keeping with the objectives of the overall program of research, special attention was paid to any references to how young people in the study prepared to leave home. 
Mann-Feder, Eades, Sobel, \& DeStefano

\section{Results}

\section{Interview results}

Themes and subthemes for home-leavers and participants at home are reported below, with supporting quotes most illustrative of the interviews.

\section{Home-leavers}

Six general themes characterized the narratives of the 16 participants who had left home: Motivation, Catalyst, Transition, Stabilizers, Destabilizers, and Adaptation (see Table 1). Overall, home-leavers characterized their process as non-linear, challenging and volatile. This was consistent with an overarching theme of ambivalence at the prospect of leaving home which participants described as the experience of excitement, fear, and self-doubt all at the same time.

These six general themes illustrate a process of home leaving that was experienced by Emerging Adults no longer living at home. At the beginning, participants described a specific motivation to leave, which developed over time. Motivators included stated reasons for wanting to leave home, and reflected a state of mind that had evolved over time. Examples included the desire to attend school away from home, to get a job, to be with a boyfriend or a girlfriend, or to experience freedom. As one participant explained, "a lot of people I was meeting in school were already self-sufficient, and I wanted that too." As stated by another participant, "I wanted to leave to be with friends. I just wanted not to be home with my parents...I wanted to go out, to party and just be with my friends 24/7."

In addition to motivation, participants explained that an identifiable catalyst stimulated their actual departure. A catalyst was described by participants as a specific opportunity or event 
that could not be passed up, which provided an immediate concrete reason for leaving. As one participant reported, "I think what really prompted my move out was also speaking with my cousin. She was in the same mind set as me". Another participant explained "My girlfriend and I got back together and then I moved in with her. Because it was easy, it could happen.” In most cases, the departure was quite sudden, although the motivation might have been building for some time, and generally participants described leaving home as a leap rather than a wellplanned exit. As one participant stated, "I had no plans. And I'm like, 'you know what? I like this place. I think I'm going to [move out of my home and] stay here."”

Participants identified a major transition that ensued after leaving home, which consisted of a period of change and uncertainty that overtook them when they actually moved. This transition was described as complex, difficult, and exciting as exemplified by the following statements: "It was a mixture of excitement and nerves at the same time," and, "I was wondering, was it going to turn out well?" Most described this initial period on their own as a crisis. A general theme was the multiple challenges that had to be confronted (cleaning, paying rent, preparing food, etc.). As one participant explained "You get home and you don't feel like cooking or something, you go, "I wish someone would make food for me.” Participants also identified a loss of control which accompanied the new experience of complete freedom. Participants described this as a tendency to "go crazy," which was characterized as an increase in excessive partying or forms of high-risk behaviours (drinking, gambling, etc.). As referred to by one participant, “Temptations. Like it's very, you know, tempting out there.”

Participants further identified factors that had contributed to how the transition itself was experienced. These factors either assisted the participants in their adjustment to independent living, or functioned as obstacles to successful adjustment. Both internal and external assets 
Mann-Feder, Eades, Sobel, \& DeStefano

acted as stabilizers. Stabilizers were sources of comfort and reassurance during the initial period once they were on their own. Most frequently cited were values, goals, and attitudes that were aligned with responsible autonomous behaviour. Participants also identified personal attributes such as determination, sense of purpose, self-confidence, and self-reliance as beneficial to their adjustment. "The more I planned it out, the more reassured I got and the less nervous I got." As another participant stated, "The confidence in yourself, to be able to do that, is the one big thing." "I believed I could do it, and not only did I believe it, like, I wanted to do it and believed I could...that helped," said one participant.

External support constituted another important stabilizer through the transition. Parents were generally mentioned as having made significant contributions to a successful move, both through helpful actions and through the provision of an emotional and financial safety net. While participants stressed that they would not want to call on their parents for help once they had moved, most acknowledged that knowing that they had back up if necessary provided reassurance. One participant noted, "Having that help readily available makes you more confident in what you decide to do." Parents also played an important role as models, and parental expressions of confidence in a young person's ability to cope were seen by almost all participants as critical stabilizers. The following quotes were characteristic of participants' comments: "That feeling of trust (from my parents) helped me...like okay they trust me so I know I can do this. I didn't have a second thought and just left." "It was actually a good time to leave because my parents were supportive of it...they saw I was in a more stable place and I had some direction." Peers were mentioned often in the narratives of home-leavers, in that they served as a source of advice and mentoring and ongoing emotional support. As explained by one participant, "I had a lot of friends living in the same area as me... if I had a question, I could call 
them. I was able to learn a lot from them." Another participant reported, "I took a lot of advice from my friends because my friends are super smart. I take advice from those people I trust and I listen to people who have information to give me. Depending on the advice they give you, it made me feel stronger, more comfortable with myself." Overall, home-leavers learned instrumental skills needed for autonomous living from peers once they had left home. All participants preferred to turn to friends for advice rather than their parents.

Furthermore, it was frequently stated that previous experience living away from home had a significant impact on the degree to which home-leavers were able to adapt. Earlier separations from home, including travel and temporary moves, were seen as an important form of preparation. Examples cited by participants were: “In sleep-away camp you don't have your parents around you and you cannot even communicate with them," "My parents have gone out of town and it's just been my brother and me...Even though I was caring for someone else it was like living on my own, but in my house." The majority of home-leavers (10) had either been away on holidays or work assignments, or had been in the family home on their own before moving out and they saw these experiences as trial runs which later acted as stabilizers.

Destabilizers were factors that contributed to increased stress during the transition period. In some cases, these ultimately impeded adaptation. Most participants experienced sadness about leaving home, and reported that the experience of loneliness could compound the weight of the added responsibility of independent living. "You are tired from your long day and papers to write and sleeping late...I didn't spend as much time with friends. So I felt as if there was a negative feeling attached to being at home," stated one participant. The individuals whose parents lived in another city were especially vulnerable: “I really missed my parents. That's a bit sad, really sad actually.” Some participants reported feeling overwhelmed by the level of 
Mann-Feder, Eades, Sobel, \& DeStefano

responsibility involved in taking care of themselves. As stated by one participant, "You come home, you have to make supper, you have to clean up and get ready for tomorrow. A minority of those interviewed reported prolonged feelings of panic coloured by resentment during the transition phase. Of note is that these home-leavers reported more negative relationships with parents and did not feel supported. As stated by one participant, "I guess parents have a big...it's their job to prepare you. If you have bad parents, the kid might suffer, because then he or she is not prepared." A small number of these participants also reported that their parents had expressed a lack of confidence in their ability to make it on their own. These home-leavers explained that their experience of leaving was infused with anger and a strong need to prove their parents wrong and that they were in fact competent to live on their own.

Beyond the transition phase, participants described a period of adaptation, a calmer time during which they settled into managing life on their own. All participants reported that over time, they got used to living independently and felt more settled emotionally. A general statement was that the instrumental skills of self-care were learned after they had left, and that mastering these skills was part of their transition, which later contributed to adaptation. As one participant stated, "I forced myself to learn how to cook and like do healthy food...so all these changes. It might be the simple things but it matters."

Of particular interest is that none of the interviewees could identify a specific preparation process that they engaged in before leaving home. Participants reported thinking primarily about the motivation for leaving home, which led to some preliminary planning related to where, and with whom they would live. This preparatory planning, which usually preceded the experience of a catalyzing event, varied in level of intensity (e.g. casual conversations with peers to informed discussions and housing searches with parents). Those who had engaged in some research and 
Leaving Home

planning thought that this has helped them to negotiate the transition, while the ability to hold on to a sense of excitement carried some participants through the challenges.

\section{Participants at Home}

Six general themes emerged from the fourteen participants who were living at home: Anticipation, Prerequisites, Benefits of Home, Parents, Peers, and Modelling (See Table 3). All participants in the study anticipated leaving home yet their projected timeline or possible reasons for going factors varied. Of the fourteen participants, only one female participant reported wanting to remain at home until marriage because of personal beliefs which were reinforced by the participant's religious and cultural community. The other thirteen participants at home cited many potential benefits of moving out, especially in relation to personal growth, freedom, and a sense of empowerment. As one participant stated, the impact of staying home indefinitely would be that "something's gonna' be missing, I'm still gonna' have this dependence and that part of my personal growth is not gonna' grow while being at home." Participants overwhelmingly endorsed the importance and the inevitability of moving out on one's own. As one participant explained, leaving home is "kind of the next move...like the natural flow of life."

The descriptions of home leaving provided by Emerging Adults at home were dominated by anticipation of what the process would be like. Themes included motivators and concerns about the transition as well as the expected impact of leaving their parents' home. The majority of participants at home identified the possible future reasons for leaving as the wish for personal space, freedom, and responsibility, while a small number made reference to social norms that would necessitate a move, especially with regards to age and the completion of post-secondary education. As one participant stated, "Slowly I'm getting these little pings of...You need to get 
Mann-Feder, Eades, Sobel, \& DeStefano

out, you need to start moving on with your life, you're going to be 22 !' While stressing the importance of moving out, participants also expressed concerns about leaving related to emotional readiness, financial resources, the ability to get along with roommates, and loneliness. As one participant explained, "I'm so paranoid of financial reasons, that I have the means to support myself." Another said, "I have a pet peeve of people ruining my time because of their irresponsibility. Such as, what if I get home and there's dishes everywhere... a mess that I didn't cause. It would be me suffering cause of them.” Many stated that while they were curious and imagined that being on their own would be a source of new maturity and pride, they were also fearful. "I think I worry a lot about being alone, like I don't want to just have an apartment by myself and find myself alone," stated one participant. Participants were also keenly aware of the benefits that living at home afforded them. Help from parents in the form of financial support and the provision of regular meals, laundry, and a clean environment was noted, as exemplified by, "Knowing that I come home to a clean home" and, "You don't have to pay for food every week." Participants recognized that living at home allowed them the freedom to do what they wanted without additional responsibilities. For some participants, the opportunity to spend time with family was also a benefit of staying at home. As one participant shared, "I think for myself emotionally it goes with myself and my parents. They look to me for emotional support and I look to them."

Participants discussed prerequisites for leaving, defined as elements that were required before they could move out. Prerequisites that were identified were resources, capacities, and trial departures from home. As described by one participant, "If you're preparing yourself to move out, you know, think positive...start saving money and be more responsible." Another 
participant at home stated, "Start doing the activities of planning...emotionally it's becoming self-aware and knowing what you want, making concrete lists of what you want."

Both parents and peers figured significantly in the narratives of participants at home, and were seen as extremely influential in relation to participants' ideas about home leaving. Most of the participants spoke often of their parents, both as a source of practical and financial support and a growing cause of irritation. Participants associated this tension with an increasing need to leave and establish a personal space. As one participant explained, leaving home would mean being "free from family... like, you know, not coming home to my mom asking questions." Many of the young people interviewed explicitly acknowledged the importance of disengaging from parents. "I want my parents to slowly step away from being in charge, and [start] letting me do things," stated one participant. At the same time, interviewees also shared worries about their parents' ability to manage without them. One participant remarked, "I'm the baby, you know. [Mom] is going to be left with my father, 24/7. It's not the ideal situation." Another stated," I do worry about my parents and how they're going to go from having two children at home to just being themselves. And I don't want to shock them."

Older siblings or peers who had already left home were mentioned often as a source of information about moving out. Peers played other major roles as potential roommates, as anticipated sources of fun and support after moving, and most importantly, as individuals who could help the participants decide whether or not to move out. "The big step would be my friend, or two of my friends, coming up and saying, 'Yeah, I'm ready to move out,"” said one participant, while another stated that she was not ready to move out because, "all my friends are living at home." Another participant shared that her friends actually discouraged her from 
Mann-Feder, Eades, Sobel, \& DeStefano

leaving, saying, “They were telling me to wait. Like they were, 'Oh, you're so lucky you are still at home."”

Beyond these roles, the participants also saw peers and siblings as models. The ability to observe others and to adopt similar strategies or avoid their mistakes provided reassurance for participants at home. It represented an opportunity to prepare for leaving though vicarious experiences, while allowing them to remain at home. As one participant stated, "Well my sister moved out a couple of years ago, so I kind of saw that transition and what she needed. It kind of prepared me to know what I need." Another participant explained, "I dated a guy...he had just moved out into an apartment, and every time I'd go there the dishes weren't done. I mean they might be boys, but I was still like 'How does this work?"'

About half of the participants at home had either been away on their own, or were planning some time away from home. As with home-leavers, a trial period was seen as an important step in preparing to leave. When speaking of a planned two-week vacation in Europe, one participant remarked, "if I can get through this trip successfully, I will know that I can live on my own.”

\section{Discussion}

The data that emerged from this study are consistent with previous literature in a range of disciplines: developmental psychology, counselling, and resilience theory. Similarities to other work will be outlined below. Conclusions drawn from the data collected by this study will then be considered to suggest a tentative model of home-leaving.

Aligned with the concept of role transition, the themes that emerged in this research confirms that leaving home is not an event, but a complex process that begins some time before 
Leaving Home

an actual departure and encompasses a period of adaptation following a move. This is consistent with formulations of Emerging Adulthood, in which the transition to adulthood is viewed as a "gradual and incremental process, which takes years to complete" (Molgat, 2007, p. 497). It is clear from the self-reports of the participants that readiness to leave home cannot be defined only in terms of instrumental skills or financial planning, but results from major shifts in family relationships and perceptions of self as separate and competent. This is in keeping with the literature on psychosocial development, which stresses the multidimensional nature of autonomy (Steinberg \& Silverberg, 1986), encompassing both relational aspects of separation/individuation and evolving cognitive functions such as self-regulation, self-determination, and decisionmaking.

Before leaving home, the young people in this study were preoccupied with disengagement from parents and the establishment of a separate sense of self. Arnett's (2000) assertion that today's young adults are working through identity issues beyond the traditional age limits of adolescence is borne out by this study, as is Tanner's formulation of the "recentering" process which starts with a shift in the parent-child relationship as a necessary first step in Emerging Adulthood (Tanner \& Arnett, 2009). The turmoil that participants in this study experienced before they left home served to intensify conflicts with parents and siblings while at the same time stimulating needs for privacy and independence. This is reminiscent of early psychodynamic formulations of the separation/individuation process, in which initially contradictory wishes operate simultaneously (Blos, 1979). Our participants expressed a desire to move away from their parents by establishing a separate residence. This interpersonal shift has been linked to intrapersonal development related to individuation (Zimmer-Gembeck, Madsen, \& Hanisch, 2011). At the same time, participants felt close to family, enjoyed many benefits 
while living at home, and worried about how their parents would cope when they left. All this served to create considerable ambivalence in relation to home leaving. The finding that virtually all of the home-leavers in this study experienced the move as a leap despite long periods of rumination beforehand, speaks to the mixed feelings they experienced about going. The actual departure reflected the impact of a catalyzing opportunity at a moment in time when the urge to go outweighed the doubt and fear. Even then, home-leavers reported that they just had to brace themselves and go. An ethnographic study of 18 year olds in Denmark documented similar findings in that young people wanted to leave home but also acknowledged that they were fearful (La Helma \& Gordon, 2002). The authors concluded that home leaving elicits a complex range of emotions, such that even young adults who perceive themselves as ready to leave may not want to move right away.

A majority of participants who had left home described the actual move as difficult, which plunged them in to a period of new responsibility accompanied by confusion, loneliness, and the potential for the loss of control. Schlossberg's (1981) transition theory, developed as framework for counselling practice, accounts for how individuals experience life transitions in stages as they "move in, through and out" of change (Goodman, Schlossberg, \& Anderson, 2009 ). According to this theory, the initial impact of a transition is disorganizing and anxiety provoking, and can be experienced both as a crisis that is beyond the individual's control, and a dangerous adventure (Goodman et al., 2009). Transitions occur in stages and require that over time the individual let go of earlier roles and "learn the ropes" so that they can adjust to their new status. This describes the experiences of the participants in this study well. Over time, as challenges were faced one by one, the uncertainty associated with moving wore off, and confidence and excitement began to build. However, not all home-leavers adapted equally well, 
and how the adjustment period unfolded was determined by factors in the individual's particular situation that had either a stabilizing or destabilizing effect.

The notion of internal and external factors that can either enhance or detract from an individual's capacity to cope has been well developed in the resilience literature. Stabilizers that assisted the home-leavers in this study to adjust are consistent with assets identified in the lives of resilient individuals. Masten (2001) summarized the most significant assets that emerged from the early research, saying that there was a "relatively small set of global factors: connections to caring adults, self-regulation skills, positive view of the self, and motivations to be effective" (p. 234, 2001). In addition to traits and attitudes that assisted in the adaptation to living autonomously, a majority of participants in this study mentioned that short separations from home were invaluable preparations for leaving home, thus serving as rehearsals. Most of the home-leavers had experienced this, and a majority of participants at home anticipated the needor expressed the desire for-for a "trial-run." This is consistent with Dowling's (2006) work, which suggests that slow experimentation and gradual attempts at leaving is a natural way to leave home. Rehearsal also turns up as helpful in Schlossberg's transitions theory, in that trial runs, "whether mental, vicarious or real, can prepare an individual for a transition" (Goodman et al., 2009, p. 34).

All participants cited parents as playing a critical role in the home leaving process. The availability of a parental safety net was generally acknowledged as an important prerequisite for leaving, as is consistent with Arnett's (2000) formulation in his theory that parental support encourages exploration and identity formation. Resilience theory also emphasizes the critical importance of parental support in an individual's life (Masten, 2001). Striking, however, is that the vast majority of both home-leavers and individuals at home hoped that they would never 
Mann-Feder, Eades, Sobel, \& DeStefano

actually have to turn to their parents for help once they had left. The perception of support was more important than whether or not participants would actually use it, as is consistent with other work on the role of social support in development (Taylor, Welch, Kim, \& Sherman, 2007). Critical, however, were parental expressions of confidence in the young people's ability to make it on their own. This is especially instructive given the well-established finding (Smetana, 2011) that parents tend to be rather conservative in underestimating their children's readiness for independence.

Participants in this study consistently identified their peers as the single most important source of external support in this home-leaving process. Friends played a critical role in the timing of departure, where they went, and how they adjusted. Participants at home looked to their friends as role models and the best source of information about when and how to leave. Those who had left home turned to friends for advice rather than to parents. This is an important finding given the dearth of research on peer relationships in the transition to adulthood. A recent longitudinal study in Germany (Seiffe-Krenke, 2010) noted a relationship between the timing of home leaving and an observed shift in measures of social support, which indicated a "transfer of support functions from parents to peers and romantic partners" (p. 512). Nonetheless, Arnett has hypothesized that "Emerging Adults may be less responsive to the influence of their friends" (2007b, p. 221), turning instead to intimate partners as their primary source of social interest and support. The central role of peers identified in this study is new contribution to both the home leaving literature and the theory of Emerging Adulthood. It has potential implications for practitioners whose mandate is to assist in the transition to autonomous living for marginalized adults.

\section{Limitations}


Given the qualitative nature of this study, the transferability of findings may be limited. While participants came from a range of ethnic and racial communities, and differing family constellations, they were all students in university. Results should thus be interpreted with caution, given that these results may only represent the home leaving experiences of middle class Canadian students. Social class has been specifically identified as a modifier of experience in Emerging Adulthood, with some scholars contending that this life stage is mostly experienced as distinct in the more affluent socio-economic groups (Tanner \& Arnett, 2009). Other researchers have also identified age, gender and ethnicity as strongly influencing home leaving (La Helma \& Gordon, 2002), and the narratives in this study were not analyzed in light of these demographic differences. There are indications that there are gendered aspects of home leaving, especially when the trajectories of youth from ethno-cultural communities are examined (Gee, Mitchell, \& Wister, 2003). This study relied on volunteers, and as such, the students who came forward to participate may have not represented a full range of home leaving experiences.

There are several other limitations of this study that may have influenced the findings. There was no attempt to group participants based on how long they had been out on their own. The data were analyzed without differentiating between young people who had just left and those who had been out for some time and there is some evidence that recency influences the accuracy with which research participants recount their experiences (Hill et al., 1997). There was also no attempt to triangulate the findings of this study. It would have been helpful to introduce standardized measures to increase the transferability of the results. Lastly, the research team was made up of a senior faculty member and two graduate students. It was clear that not only did the whole team share a strong belief in the importance of home leaving for wellbeing in the transition to adulthood; the faculty member was the parent of young adults who were in the 
Mann-Feder, Eades, Sobel, \& DeStefano

process of leaving home while both graduate students had strong memories of their own home leaving experiences. This enriched the discussions of the data but may have introduced bias into the analysis.

\section{Implications}

The findings from this study address a gap in our understanding of an important developmental process that may influence the course of adult life (De Marco \& Cosner Berzin, 2008). The results have implications both for practice and for future research.

Indications from this research are that moving out on one's own represents a significant transition which constitutes a crisis for many young people. The ambivalence, and even the irritation, that young adults can exhibit towards their parents may be a necessary step in the development of autonomy, and should not be misinterpreted as rejection, or a signal that parents need no longer play a role in the lives of Emerging Adults. At the same time, the results of this study suggest that the instability that moving out creates is part of a developmental transition that should not be pathologized or mistaken for an inability to cope. Parental supports, and especially parental encouragement, are vital ingredients in assisting home-leavers to adjust to life on their own.

For many years, outcome studies with marginalized young people from a range of settings (child welfare, mental health, juvenile justice) have stressed the difficulties that these young people face in transitioning to autonomous living when services end at age of majority (Osgood et al., 2005). Consequently there has been significant investment, both in North America and in Europe, in programs of preparation that teach life skills and support young people in the instrumental aspects of moving out. While results of the current study reemphasize that the lack of family support may exacerbate the challenges of moving out on one's own, 
Leaving Home

young people from placement settings will inevitably struggle as all home-leavers do. At the same time, investment in teaching skills of daily living per se may do little to assist individuals through the inevitable ups and downs of adjusting to life on one's own. A far better approach may be to focus on interventions that strengthen self-esteem and the capacity for self- regulation, while emphasizing the need for social support. While not all young people can count on parents, peers are a naturally occurring resource in all settings where young people grow up. Programs and policies that support normative peer relationships for youth can help build social skills. Thus, this study provides a new focus for intervention and applied research, as it seems that a range of peer oriented interventions, including peer mentoring and community building, may be particularly relevant for supporting youth who are moving out on their own.

A focus on peers generally, and their role in the transition to adulthood, is a new area to explore in the study of Emerging Adulthood. The importance of peer relationships for adjustment has been well documented in child and adolescent development, but has been largely neglected in the literature of Emerging Adulthood in favour of a focus on romantic partnerships. This study suggests that peers continue to play a critical role in development, and, as is documented in earlier life stages, may provide unique input not available elsewhere. In addition, research that encompasses the home leaving experiences of young people from a range of socioeconomic and cultural backgrounds, including those who are not attending university, is sorely needed to expand the state of knowledge about this significant developmental stage. 
Mann-Feder, Eades, Sobel, \& DeStefano

Table 1: CQR Themes and Sub-themes for Home-leavers

$\begin{array}{llll}\text { Theme Sub-theme } & \begin{array}{l}\text { General } \\ (\mathbf{1 0 0 \%})\end{array} & \begin{array}{l}\text { Typical } \\ (\mathbf{5 0 \%}+\mathbf{1})\end{array} & \begin{array}{l}\text { Variant } \\ (<\mathbf{5 0 \%})\end{array}\end{array}$

1) Motivations

Ambivalence

$\mathrm{X}$

Worry about parents

Anxiety or fear

Worry about money

Leaving for school

$\mathrm{X}$

Leaving for job

Leaving for relationship

Leaving for more freedom

Leaving to get away

Leaving to have a

different experience

Not their choice

$\mathrm{X}$
$\mathrm{X}$
$\mathrm{X}$
$\mathrm{X}$

X

$\mathrm{X}$

$\mathrm{X}$

X

X

$\mathrm{X}$

2) Catalysts

X

Opportunity for an

Apartment

$\mathrm{X}$

Opportunity to live with a friend

Opportunity for a job

X

X

3) Transition
Crisis
Challenges of managing with cleaning, cooking, money

Going crazy, loss of control

$\mathrm{X}$

4) Adaptation

Getting settled

$\mathrm{X}$

New insight

$\mathrm{X}$

$\mathrm{X}$

$\mathrm{X}$

5) StabilizersInternal assets

Self-confidence

Previous Experiences

Determination, sense of purpose

Planning

Sense of excitement

Values

$\mathrm{X}$

$\begin{array}{ll}\mathrm{X} & \\ \mathrm{X} & \mathrm{X} \\ & \mathrm{X} \\ & \mathrm{X} \\ & \mathrm{X} \\ & \mathrm{X}\end{array}$


Leaving Home

Table 1, cont.

\begin{tabular}{|c|c|c|c|c|}
\hline Theme & Sub-theme & $\begin{array}{l}\text { General } \\
(100 \%)\end{array}$ & $\begin{array}{l}\text { Typical } \\
(50 \%+1)\end{array}$ & $\begin{array}{l}\text { Variant } \\
(<50 \%)\end{array}$ \\
\hline & $\begin{array}{l}\text { Goals } \\
\text { Attitudes } \\
\text { External Assets } \\
\text { Parental safety net } \\
\text { Parental expressions } \\
\quad \text { of confidence } \\
\text { Parents as role models } \\
\text { Peer mentors } \\
\text { Peer support }\end{array}$ & $\begin{array}{l}X \\
X\end{array}$ & $\begin{array}{l}X \\
X \\
X \\
X\end{array}$ & $\begin{array}{l}X \\
X\end{array}$ \\
\hline 6) Desta & $\begin{array}{l}\text { lizers } \\
\text { Sadness } \\
\text { Loneliness } \\
\text { Anger } \\
\text { Resentment } \\
\text { Feeling Overwhelmed } \\
\text { Missing parents because } \\
\text { of distance }\end{array}$ & & $\begin{array}{l}X \\
X\end{array}$ & $\begin{array}{l}X \\
X \\
X \\
X \\
X\end{array}$ \\
\hline
\end{tabular}


Mann-Feder, Eades, Sobel, \& DeStefano

Table 2: CQR Themes and Sub-themes for Participants at Home

$\begin{array}{llll}\text { Theme Sub-theme } & \begin{array}{l}\text { General } \\ (\mathbf{1 0 0 \%})\end{array} & \begin{array}{l}\text { Typical } \\ (\mathbf{5 0 \%}+\mathbf{1})\end{array} & \begin{array}{l}\text { Variant } \\ (<\mathbf{5 0 \%})\end{array}\end{array}$

1) Anticipation $X$

Motivation X

Own space $\quad \mathrm{X}$

Independence $\quad \mathrm{X}$

Responsibility $\quad \mathrm{X}$

Personal Growth $\quad X$

Being alone

Freedom

Privacy

Making choices

For sake of experience

Social norms

Independence

Personal growth

Separate from Parents

Feelings of accomplishment

$X$

$\mathrm{X}$

$\mathrm{X}$

$\mathrm{X}$

$\mathrm{X}$

$\mathrm{X}$

$\mathrm{X}$

Concerns

Money

Loneliness

Room-mates

X

$\mathrm{X}$

$\mathrm{X}$

$X$

$\mathrm{X}$

2) Prerequisites

Financial Resources

Capacities Skills

Sense of self

$\mathrm{X}$

$\mathrm{X}$

X

$\mathrm{X}$

$X$
$X$

3) Benefits of home

Financial/instrumental support

Freedom to do what I want

Being with family

$\mathrm{X}$

$\mathrm{X}$

X

$\mathrm{X}$

4) Parents

X

Irritant

Source of support

Worries about them

$X$
$X$

X 
Leaving Home

Table 2, cont.

Theme Sub-theme

General

Typical

Variant

(100\%)

$(50 \%+1)$ $(<50 \%)$

5) Peers

X

Potential roommates

Benefit to be with them

Influence to leave or not

$X$
$X$

X

6) Modelling

Siblings

Friends

X

$\mathrm{X}$

X

7) Importance of Trial

X 


\section{References}

Arnett, J.J. (2007a). Aging out of care: Toward realizing the possibilities of emerging adulthood. In Mann-Feder, V. (Ed.) Transition or Eviction? Youth exiting care for independent living. New Directions in Youth Development, 113, 151-161.

Arnett. J.J. (2007b). Socialization in Emerging Adulthood: From the family to the wider world, from socialization to self-socialization. In Grusec, J. \& Hastings, P.D. (Eds.) Handbook of Socialization: Theory and research (pp.208-231). New York: Guilford.

Arnett, J.J. (2000). Emerging adulthood: A theory of development from the late teens through the twenties. American Psychologist, 55, 469-480.

Blos, P. (1979). The Adolescent Passage: Developmental Issues. New York: International Universities Press.

Clark, W. (2009). Delayed transitions of young adults. Canadian Social Trends: Statistics Canada. Retrieved April 19, 2012 from http://www.statcan.gc.ca/pub/11-08x/2007004/10311-eng.htm

De Marco, A.C. \& Cosner Berzin, S. (2008). The influence of family economic status on homeleaving patterns during Emerging Adulthood. Families in Society, 89 (2), 208-218.

Dowling, D. (2006). The capacity to be alone: Rediscovering Winnicott and his relevance to parent-infant psychotherapy. In A question of technique: Independent psychoanalytic approaches with children and adolescents. Retrieved February 1, 2009, from http://0search.ebscohost.com.mercury.concordia.ca

Furstenberg, F., Rumbaut, R.C., Settersen, R.A. (2005). On the frontier of adulthood: Emerging themes and new directions. In Settersen, R.A.; Furstenberg, F. \& Rumbaut, R.C. (Eds.) On the frontier of adulthood: Theory, research and public policy (pp.3-28). Chicago: University of Chicago Press.

Gee, E.M., Mitchell, B.A., \&Wister, A.W. (2003). Home leaving trajectories in Canada: Exploring cultural and gendered dimensions. Canadian Studies in Population, 30(2), 245-270.

Goodman, J., Schlossberg, N., \& Anderson, M.L. (2006). Counseling Adults in Transition: Linking practice with theory. $\left(3^{\text {rd }}\right.$. Ed.) New York: Springer.

Hill, C., Thompson, B., \& Williams, E. (1997). A guide to conducting Consensual Qualitative Research. The Counselling Psychologist, 25(4), 517-572. 
Human Resources and Skill Development Canada (2013). Indicators of well-being in Canada: Family Life-Marriage. Retrieved March 9, 2013 from www4.hrsdc.ga/ .3ndic.1t.4r@eng.jsp?iid+78.

LaHelma, E. \& Gordon, T. (2003). Home as a physical, social and mental space: Young people's reflections on leaving home. Journal of Youth Studies, 6(4), 377-390.

Lamborn, S. \& Groh, K. (2009). A four-part model of autonomy during Emerging Adulthood: Associations with adjustment. International Journal of Behavioral Development, 33(5), 393-401.

Mann-Feder, V. (2007). Issue editor`s notes. In Mann-Feder, V. (Ed.) Transition or Eviction? Youth exiting care for independent living. New Directions in Youth Development, 113, $1-8$.

Mann-Feder, V. (2011). Intervening with youth in the transition to independent living. Journal of Child and Youth Care Work, 23, 8-13.

Masten, A.S. (2001). Ordinary magic: Resilience processes in development. American Psychologist, 56(3), 227-238.

Mitchell, B.A. (2006). The Boomerang Age: Transitions to Adulthood in Families. New Jersey: Aldine-Transaction.

Molgat, M. (2007). Do transitions and social structure matter? How Emerging Adults define themselves as adults. Journal of Youth Studies, 10 (5), 495-516.

Molgat, M. (2002). Leaving home in Quebec: Theoretical and social implications of (Im)mobility among youth. Journal of Youth Studies, 5(2), 135-152.

Mulder, C. (2009). Leaving the parental home in young adulthood. In Furlong, A. (Ed.) Handbook of Youth and Young Adulthood, (pp.203-210). London: Routledge.

Osgood, D., Foster, E., Flanagan, C. \& Ruth, C. (2005). Why focus on the transition to adulthood for vulnerable populations. In Osgood, W., Foster, E., Flanagan, C. \& Ruth, C. (Eds.) On your own without a net: The transition to adulthood for vulnerable populations, (pp. 1-26). Chicago: University of Chicago Press.

Proudfoot, P. (2010). You can go home again. Montreal Gazette, October 5. Reid, C. \& Dudding, P. (2007). Building a future together: Issues and outcomes for transition aged youth. Ottawa: Centre of Excellence for Child Welfare.

Schlossberg, N. (1981). A model for analyzing human adaptation to transition. The Counseling Psychologist, 9(2), 2-18. 
Seiffge-Krenke, I. (2010). Predicting the timing of leaving home and related developmental tasks:

Parents' and children's perspectives. Journal of Social and Personal Relationships, 27 (4), 495-518.

Smetana, J.G. (2011). Adolescents, families, and social development: How teens construct their world. Malden, Massachusetts: Wiley-Blackwell.

Statistics Canada (2011). Living arrangements of young adults aged 20-29. Available at: http://www12.statcan.gc.ca/census-recensement/2011/as-sa.

Steinberg, L. \& Silverberg, S.B. (1986). The vicissitudes of autonomy in early adolescence. Child Development, 57, 841-851.

Tanner, J. \& Arnett, JJ. (2009). The emergence of "emerging adulthood": The new life stage between adolescence and young adulthood. In Furlong, A. (Ed) Handbook of Youth and Young Adulthood (pp.39-46). London: Routledge.

Taylor, Welch, Kim \& Sherman (2007). Cultural differences in the impact of social support on psychological and biological stress response. Psychological Science, 18, 831-837.

Tweddle. A. (2007). Youth leaving care: How do they fare? In Mann-Feder, V. (Ed.) Transition or Eviction? Youth exiting care for independent living. New Directions in Youth Development, 113, 15-32.

Zimmer-Gembeck, M., Madsen, S.D. \& Hanisch, M. (2011). Connecting the intrapersonal to the interpersonal: Autonomy, voice, parents and romantic relationships in emerging adulthood. European Journal of Developmental Psychology, 8 (5), 509-525. 